\title{
Distribution and stability of supernumerary microchromosomes in natural populations of the Amazon molly, Poecilia formosa.
}

\author{
Lamatsch, D K ; Nanda, I ; Schlupp, I ; Epplen, J T ; Schmid, M ; Schartl, M
}

\begin{abstract}
In animals, supernumerary chromosomes and their evolution have mostly been studied in sexual reproducing species. In the present study, for the first time, the natural distribution and stability of supernumerary microchromosomes were investigated in the unisexual fish species Poecilia formosa. Natural habitats throughout the range of P. formosa were screened for the presence of microchromosomes over several years. A high frequency of microchromosomes was found in the Río Purificación river system. Evidence points to the presence of the same microchromosome lineage over many generations. No supernumerary chromosomes were found elsewhere than in the Río Purificación representing a significant difference in the distribution of microchromosome-bearing individuals between the Río Purificación and all other collection sites.
\end{abstract}

DOI: https://doi.org/10.1159/000079286

Posted at the Zurich Open Repository and Archive, University of Zurich ZORA URL: https://doi.org/10.5167/uzh-553

Journal Article

Published Version

Originally published at:

Lamatsch, D K; Nanda, I; Schlupp, I; Epplen, J T; Schmid, M; Schartl, M (2004). Distribution and stability of supernumerary microchromosomes in natural populations of the Amazon molly, Poecilia formosa. Cytogenetic and Genome Research, 106(2-4):189-194.

DOI: https://doi.org/10.1159/000079286 


\title{
Distribution and stability of supernumerary microchromosomes in natural populations of the Amazon molly, Poecilia formosa
}

\author{
D.K. Lamatsch, ${ }^{a}$ I. Nanda, ${ }^{b}$ I. Schlupp, ${ }^{c}$ J.T. Epplen, ${ }^{d}$ M. Schmid ${ }^{b}$ and \\ M. Schartla \\ Institutes of a Physiological Chemistry I and ${ }^{b}$ Human Genetics, Biocenter, University of Würzburg, Würzburg (Germany); \\ c Zoologisches Institut, Universität Zürich, Zürich (Switzerland); \\ ${ }^{\mathrm{d}}$ Human Genetics, Ruhr-Universität Bochum, Bochum (Germany)
}

\begin{abstract}
In animals, supernumerary chromosomes and their evolution have mostly been studied in sexual reproducing species. In the present study, for the first time, the natural distribution and stability of supernumerary microchromosomes were investigated in the unisexual fish species Poecilia formosa. Natural habitats throughout the range of $P$. formosa were screened for the presence of microchromosomes over several years. A high frequency of microchromosomes was found in the
\end{abstract}

Río Purificación river system. Evidence points to the presence of the same microchromosome lineage over many generations. No supernumerary chromosomes were found elsewhere than in the Río Purificación representing a significant difference in the distribution of microchromosome-bearing individuals between the Río Purificación and all other collection sites.

Copyright $\odot 2004$ S. Karger AG, Basel
Supernumerary chromosomes, also called B chromosomes, have been found in all major groups of plants and animals (Jones and Rees, 1982). Their occurrence in fishes has been described earlier. In addition to the 21 fish species listed by Salvador and Moreira-Filho (1992), five other species have been reported to have supernumerary chromosomes (Vicente et al., 1996). They vary greatly in size from microchromosomes (e.g. in Prochilodus scrofa, Pauls and Bertollo, 1983; and Moenkhausia sanctaefilomenae, Foresti et al., 1989), to medium-sized chromosomes (e.g. Rhamdia hilarii, Fenocchio and Bertollo, 1990) or even macrochromosomes (Astyanax scabri-

\footnotetext{
Supported by the DFG (SFB 567 Mechanismen der interspezifischen Interaktion von Organismen) and Fonds der Chemischen Industrie.

Received 28 October 2003; revision accepted 23 January 2004.

Request reprints from Dunja Lamatsch, Institute of Physiological Chemistry I Biocenter, Am Hubland, University of Würzburg

DE-97074 Würzburg (Germany); telephone: +49 9318884152

fax: +49931888 4150; e-mail: lamatsch@biozentrum.uni-wuerzburg.de
}

pinnis, Maistro et al., 1992; Alburnus alburnus, Ziegler et al., 2003).

Two primary sources for $\mathrm{B}$ chromosomes have been considered (Jones and Rees, 1982; Green, 1990; Camacho et al., 2000): either an intragenomic fragment acquires the characteristics of a B chromosome from duplicated or fragmented pieces within a genome, or interspecific hybridization provides foreign DNA from a closely related species that evolves into a supernumerary chromosome.

P. formosa, commonly called Amazon molly, is a small freshwater fish distributed in southern Texas and northeastern Mexico (Schlupp et al., 2002). It was the first unisexual vertebrate to be described (Hubbs and Hubbs, 1932). Its mode of reproduction is gynogenesis (Kallman, 1962) which is defined as sperm-dependent parthenogenesis. Normally, females produce unreduced diploid eggs which are only activated for embryogenesis by sperm of males of closely related species (P. mexicana, P. latipinna, P. latipunctata, Schlupp et al., 2002). Therefore, the offspring is genetically identical to the mother. Supernumerary chromosomes in this species most probably result from a failure in the mechanism, which clears the egg from the sperm nucleus. The interspecific origin could be demonstrated for individuals who expressed a paternal

\footnotetext{
KARGER Fax +41613061234 E-mail karger@karger.ch www.karger.com

(C) 2004 S. Karger AG, Basel 0301-0171/04/1064-0189\$21.00/0
}

Accessible online at: www. karger.com/cgr 
Fig. 1. Map of the different collection sites in northeastern Mexico and southern Texas as listed in Table 1. Spotted lines are streets (see Balsano et al., 1972). San Marcos (not shown in map) is an introduced population from Caldwell County in central Texas. Source of the introduction was Brownsville (Schlupp et al., 2002).

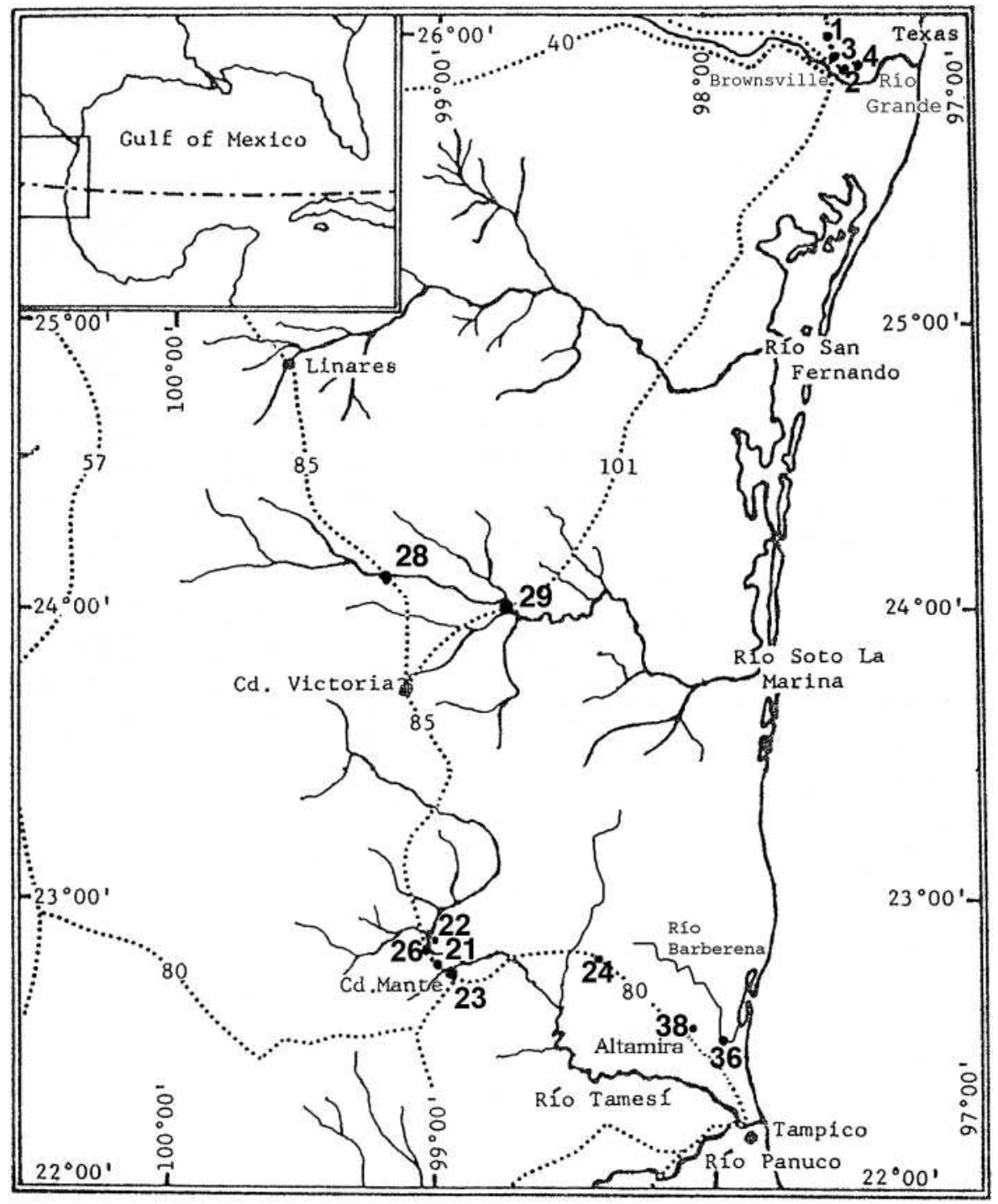

macromelanophore locus resulting in spotted individuals (Schartl et al., 1995, 1997). Macromelanophores are a pigment cell type specific to the Black molly, an ornamented Poecilia strain selected for its black body pigmentation. Such Black mollies are commonly used as host males in the laboratory. This is a very rare situation since normally supernumerary chromosomes are considered to be genetically inert (Jones and Rees, 1982). In the Amazon molly, not only the above described microchromosomes of Black molly origin exist, but also naturally occurring microchromosomes in wild-type individuals have been seen (Sola et al., 1993).

In the genus Poecilia the karyotype usually shows 46 subtelocentric and acrocentric chromosomes (for an overview see Prehn and Rasch, 1969; Haaf and Schmid, 1984; Sola et al., 1992a; Schartl et al., 1995; Rodionova et al., 1996). In P. formo$s a$ different chromosomal clones have been described, mostly based on different nucleolus organizer region (NOR) positions (Sola et al., 1997), or heteromorphism of the short arms of chromosome pair 1 (Sola et al., 1992b).
In the present study the natural distribution and the stability of microchromosome bearing $P$. formosa lineages was studied over several years. We screened natural habitats throughout the range of the Amazon molly for the presence of microchromosomes. Animals bearing microchromosomes were bred for one generation to study whether the microchromosomes are transmitted stably to their offspring. We found a high frequency of microchromosomes in the Río Purificación river system, whereas in other parts of the natural range of $P$. formosa this phenomenon appears to be rare or absent. Evidence was obtained that points towards the presence of the same microchromosome over many generations.

\section{Materials and methods}

Fishes

All experimental fish were kept in the aquarium of the Biocenter of the University of Würzburg under standard conditions. Wild fish were from the different collection sites in northeastern Mexico and Texas (Table 1, Fig. 1). 

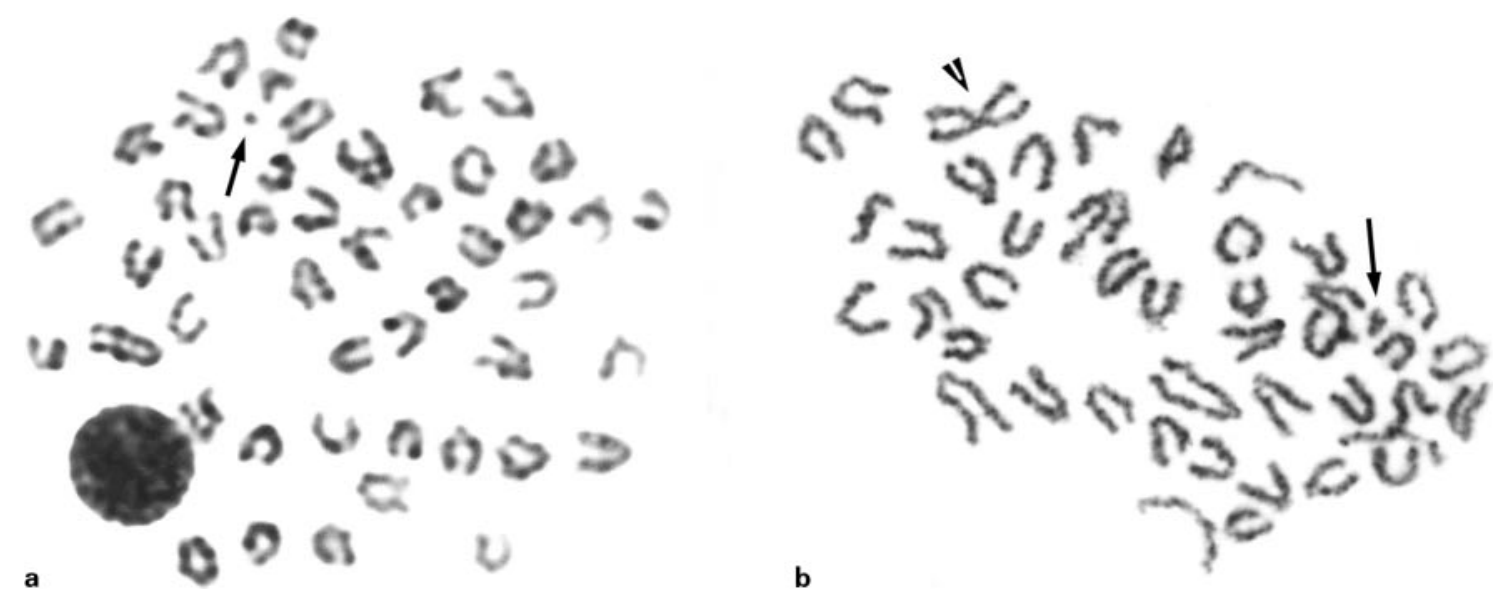

Fig. 2. Representative Giemsa-stained metaphases showing the presence of a single accessory (a) tiny and (b) large microchromosome in specimens of unisexual Amazon molly from the Río Purificación population. Arrows indicate the microchromosomes. Note the presence of a large metacentric chromosome (arrowhead) in $2 n=45$ specimens with the larger microchromosome in $\mathbf{b}$.

Cytogenetic analyses

Cytogenetic analyses were carried out according to Nanda et al. (1995). Chromosomes were Giemsa-stained. At least 10 Giemsa-stained metaphases were counted for each individual.

\section{Multilocus DNA fingerprinting}

DNA was extracted using EDTA buffer and phenol/chloroform according to the method of Blin and Stafford (1976). HinfI was used for restriction digestion, and the restriction fragments were separated on a $0.8 \%$ agarose gel at $1 \mathrm{~V} / \mathrm{cm}$. In-gel hybridization was done essentially as described by Nanda et al. (1988). The ${ }^{32} \mathrm{P}$-labeled oligonucleotides $(\mathrm{GATA})_{4},(\mathrm{GGAT})_{4},(\mathrm{GA})_{8}$, and $(\mathrm{CA})_{8}$ specific to hypervariable simple repeats were used as hybridization probes.

\section{Results}

A total of 129 individuals collected between 1993 and 2002 from 14 different sites were analyzed (Fig. 1). In addition to karyotypically normal $(2 \mathrm{n}=46)$ diploid specimens $(\mathrm{N}=101)$, metaphases from 28 individuals showed a microchromosome. All metaphases analyzed from these microchromosome-carrying specimens conspicuously had a single microchromosome (Fig. 2). Thus the microchromosome appears to be mitotically stable. Further detailed analysis uncovered that some of these microchromosome-bearing individuals had one unpaired large metacentric chromosome and their diploid number was 45 instead. Due to its small size, it was not possible to detect specific features of the microchromosome using traditional cytogenetic methods. Intriguingly, microchromosomes were only found in females from the Río Purificación. Out of 28 females carrying microchromosomes, 7 individuals showed the normal $2 n=46$ chromosome complement with one tiny microchromosome $(2 \mathrm{n}=46+\mathrm{m})$ (Fig. 2a). Fourteen individuals, however, were pseudoaneuploid with a diploid chromosome number of 45 , and their karyotype displayed one large metacentric chromosome and a larger microchromosome $(2 n=45+F+M)$ (Fig. $2 b)$. Seven individuals showed a triploid karyotype with one tiny microchromosome of the same type as in the diploid karyotype $(3 n=69+m)$. The frequency of microchromosomes in the Río Purificación (28 with and 47 without, $37.33 \%$ ) differs significantly from the frequency at all other collection sites $(0$ with and 54 without $)\left(\chi^{2}\right.$ test, $\mathrm{df}=1, \chi^{2}=23.61, P<0.0001$; $\mathrm{cf}$. Table 1). Individuals carrying microchromosomes or triploids do not differ phenotypically from diploid individuals.

Multilocus DNA fingerprinting of the microchromosomebearing fishes revealed that one analyzed female showing the tiny microchromosome $(2 n=46+m)$ belongs to clone $f$ (Fig. 3$)$, a frequent clone among diploid $P$. formosa (Lampert et al., 2004). This means that either a fish from clone $f$ has acquired the microchromosome, or alternatively most of the fish of clone $f$ have lost it.

Surprisingly, eleven analyzed females possessing the larger microchromosome $(45+\mathrm{F}+\mathrm{M})$ belong to six different clones. Clone $b^{\prime}$ shows one additional band to the overall identical banding pattern of clone $b$, whereas $c^{\prime}$ differed from clone $\mathrm{c}$ in lacking only one band (Fig. 3). Overall, the basic banding pattern of all clones is quite similar. These clones could not be found in 39 additionally analyzed diploid individuals (data not shown). Two triploid individuals with the tiny microchromosome were analyzed by multilocus DNA fingerprinting. They resemble two different clones ( $C$ and $E$ ). Whereas clone $D$ is represented by this individual only, clone $C$ is frequent among triploid animals (Lampert et al., 2004).

One female of each microchromosome-bearing clone was mated to a Black molly male, and the offspring was analyzed cytogenetically for the presence of the different microchromosomes. It could be shown that the females of the three different clones $(2 n=46+m, 2 n=45+F+M, 3 n=69+m)$ transmitted their microchromosomes to the next generation $(\mathrm{N}=5, \mathrm{~N}=1$, and $\mathrm{N}=4$, respectively). 
Table 1. Number and type of microchromosomes found in P. formosa from natural populations in northeastern Mexico and southern Texas. $2 n=46$ refers to animals without microchromosomes. $2 n=46+m$ and $3 n=69+m$ refer to diploid and triploid specimens with a single tiny microchromosome, respectively. Animals showing the large metacentric chromosome and a larger microchromosome are referred to as $2 n=45+F+M$. Note that microchromosomes were only found in the Rio Purificación populations. Numbers of collection sites as given in Fig. 1.

\begin{tabular}{|c|c|c|c|c|c|c|c|c|}
\hline & Locality & Collection site no. & Year & $2 n=46$ & $2 n=46+m$ & $2 \mathrm{n}=45+\mathrm{F}+\mathrm{M}$ & $3 n=69+m$ & $\mathrm{~N}$ \\
\hline \multirow[t]{16}{*}{ Mexico } & Rio Purificación, Barretal & 28 & 1993 & 2 & 2 & 1 & - & 5 \\
\hline & & & 1996 & $29^{\mathrm{a}}$ & 3 & 12 & - & 44 \\
\hline & & & 1998 & 8 & - & 1 & 5 & 14 \\
\hline & & & 2002 & 3 & 2 & - & 1 & 6 \\
\hline & Rio Purificación, Nuevo Padilla & 29 & 1993 & 1 & - & - & - & 1 \\
\hline & & & 1996 & 3 & - & - & - & 3 \\
\hline & & & 1998 & 1 & - & - & 1 & 2 \\
\hline & Rio Barberena, near Lomas del Real & 36 & 1994 & 2 & - & - & - & 2 \\
\hline & Rio Guayalejo, near El Limón & 22 & 1993 & 1 & - & - & - & 1 \\
\hline & Mante & 23 & 1993 & 1 & - & - & - & 1 \\
\hline & Ditch north of Mante & 21 & 1993 & 2 & - & - & - & 2 \\
\hline & & & 1998 & 5 & - & - & - & 5 \\
\hline & near González (Mex 80) & 24 & 1993 & 3 & - & - & - & 3 \\
\hline & Rio Guayalejo (Mex 85) & 26 & 1998 & 1 & - & - & - & 1 \\
\hline & Laguna Champaxan near Altamira & 38 & 1994 & 3 & - & - & - & 3 \\
\hline & & & 2002 & 8 & - & - & - & 8 \\
\hline \multirow[t]{5}{*}{ Texas } & Northmost & 1 & 1994 & 1 & - & - & - & 1 \\
\hline & Brownsville & 2 & 1994 & 5 & - & - & - & 5 \\
\hline & Olmito & 3 & 1995 & $2^{a}$ & - & - & - & 2 \\
\hline & Bay View & 4 & 1995 & 2 & - & - & - & 2 \\
\hline & San Marcos & & 1994 & $18^{\mathrm{a}}$ & - & - & - & 18 \\
\hline
\end{tabular}

\section{Discussion}

In the genus Poecilia the karyotype usually shows 46 subtelocentric or acrocentric chromosomes (Prehn and Rasch, 1969; Haaf and Schmid, 1984; Sola et al., 1992a; Rodionova et al., 1996). In cytogenetic studies on $P$. formosa only very small sample sizes have been analyzed up to date. Different chromosomal clones have been described in P. formosa, mostly based on different NOR positions (Sola et al., 1997), or heteromorphism of the short arms of chromosome pair 1 (Sola et al., 1992b). Sola et al. (1993) described a single individual out of six investigated fish from the Río Purificación, Nuevo Padilla, Mexico, showing an unpaired metacentric chromosome and a larger microchromosome. In addition, the authors found a triploid individual also showing a single microchromosome.

We report here, for the first time, on an extensive screening of different populations of $P$. formosa focusing on microchromosomes. It is noteworthy that we found the single tiny microchromosome in four different sampling years. No supernumerary chromosomes were found elsewhere than in the Río Purificación. Obviously, there is a significant difference in the distribution of microchromosome-bearing individuals between the Río Purificación and all other collection sites. Thus the Río Purificación may represent a hot-spot for the presence of microchromosomes. Several reasons may explain this pattern: the probability of de novo origin of microchromosomes at other sites may be very low, and/or the conditions for the persistence of such clones may be exceptionally favorable in the Río Purificación. Alternatively, it cannot be excluded that future samplings may reveal the existence of microchromosome-bearing clones at other sites.

As analyzed by multilocus DNA fingerprinting, the eleven females possessing the larger microchromosome $(45+\mathrm{F}+\mathrm{M})$ belong to six different clones. Taking into account that a similar banding pattern could not be found among 39 diploid individuals analyzed additionally, it is likely that this karyotype evolved only once, and that the observed intraclonal genetic differences are due to mutations that occurred afterwards. The existence of six clearly distinguishable clones points to the fact that many generations must have passed since their common origin because, in general, the mutation rate apparent in different DNA fingerprint patterns is very low in $P$. formosa.

Finding these different clones in subsequent years in the Río Purificación suggests them to be a stable component of the population. In addition, we could show that all offspring tested from the following generation invariantly had the same karyotype as their mothers, including the tiny microchromosome or the metacentric chromosome plus the larger microchromosome.

In summary, our study provides some information of the distribution and stability of accessory chromosomes in the genome of the asexual Amazon molly in natural condition. It is 
Fig. 3. Multilocus DNA fingerprint of one diploid animal with one tiny microchromosome $(2 n=46+m)$ belonging to the common diploid clone $f$ also found in animals without microchromosomes. Eleven individuals with the unpaired metacentric fusion chromosome and the larger microchromosome $(45+\mathrm{F}+\mathrm{M})$ making up six different clones with a very similar basic banding pattern. In-gel hybridization with ${ }^{32}$ P-labeled oligonucleotide $(\mathrm{GGAT})_{4}$. Two triploid individuals with one tiny microchromosome $(3 n=$ $69+\mathrm{m}$ ). Whereas clone $E$ is made up of this single individual only, clone $C$ is frequent among triploids. In-gel hybridization with ${ }^{32} \mathrm{P}$-labeled oligonucleotide $(\mathrm{GT})_{8}$.

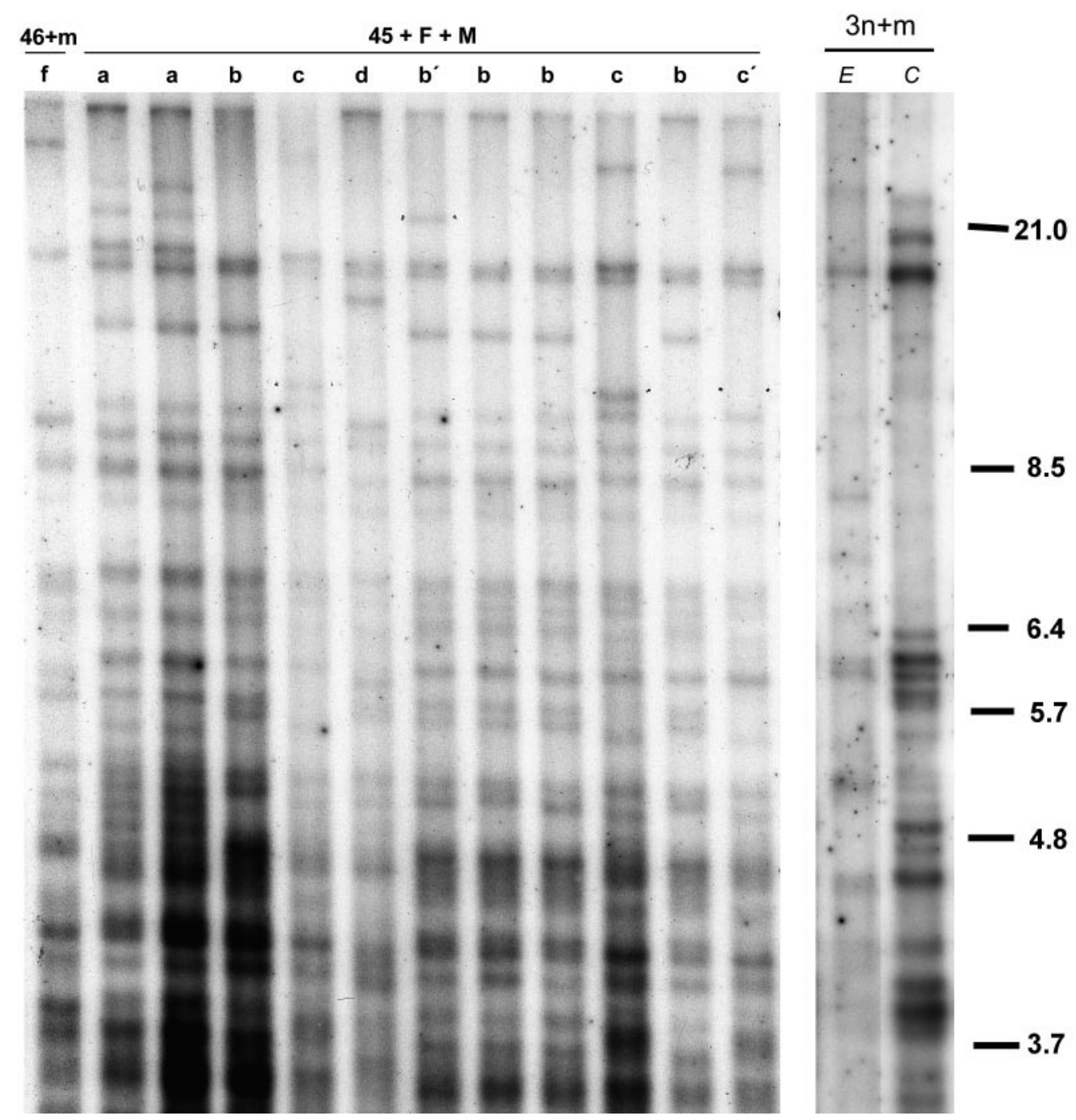

reproducing animals. Absence of normal meiosis among asexually reproducing vertebrates like the Amazon molly may render to retain this small marker chromosome. In this regard, a fluorescence in situ hybridization experiment with a microdissected microchromosome paint is necessary for precise detection of the breakpoints preceding the centromeric fusion, and to prove that the small microchromosome indeed is an intragenomic segment.

In asexual (clonal) organisms mutations are usually the only source of genetic variability. In the case of the Amazon molly, microchromosomes play a role as an additional source of genetic variability, but their function and evolutionary significance remain to be tested.

\section{Acknowledgements}

We are grateful to the Mexican government for issuing permit no. 210696-213-03 and two fishing licenses (Texas) to collect $P$. formosa, and to J. Parzefall, M. Döbler, I. Schlupp, K. Körner, U. Hornung and A. Froschauer and local people at Barretal for help in the field. We thank H. Schwind, G. Schneider and P. Weber for breeding of the fish in the laboratory, and P. Fischer and M. Hidding for technical support. 


\section{References}

Balsano JS, Darnell RM, Abramoff P: Electrophoretic evidence of triploidy associated with populations of the gynogenetic teleost Poecilia formosa. Copeia 2:292-297 (1972).

Blin N, Stafford DW: A general method for isolation of high molecular weight DNA from eukaryotes. $\mathrm{Nu}-$ cleic Acids Res 3:2303-2308 (1976).

Camacho JP, Sharbel TF, Beukeboom LW: B-chromosome evolution. Philos Trans R Soc Lond B Biol Sci 355:163-178 (2000).

Fenocchio AS, Bertollo LA: Supernumerary chromosome in a Rhamdia hilarii population (Pisces, $\mathrm{Pi}$ melodidae). Genetica 81:193-198 (1990).

Foresti F, Almeida-Toledo LF, Toledo FS: Supernumerary chromosome system, C-banding pattern characterization, and multiple nucleolus organizer regions in Moenkhausia sanctaefilomenae (Pisces, Characidae). Genetica 79:107-114 (1989).

Green DM: Muller's ratchet and the evolution of supernumerary chromosomes. Genome 33:818-824 (1990).

Haaf T, Schmid M: An early stage of ZW/ZZ sex chromosome differentiation in Poecilia shenops var melanistica (Poeciliidae, Cyprinodontiformes). Chromosoma 89:37-41 (1984).

Holmquist GP, Dancis B: Telomere replication, kinetochore organizers, satellite DNA evolution. Proc Natl Acad Sci USA 76:4566-4570 (1979).

Hubbs CL, Hubbs LC: Apparent parthenogenesis in nature, in a form of fish of hybrid origin. Science 76:628-630 (1932).

Jones RN, Rees H: B chromosomes (Academic Press, New York 1982).

Kallman KD: Gynogenesis in the teleost, $M$. formosa, with discussion of the detection of parthenogenesis in vertebrates by tissue transplantation. J Gene 58:7-21 (1962).
Maistro EL, Foresti F, Oliveira C, Almeida-Toledo LF: Occurrence of macro B chromosomes in Astyanax scabripinnis paranae (Pisces, Characiformes, Characidae). Genetica 87:101-106 (1992).

Nanda I, Neitzel H, Sperling K, Studer R, Epplen JT: Simple GATCA repeats characterize the X chromosomal heterochromatin of Microtus agrestis, European field vole (Rodentia, Cricetidae). Chromosoma 96:213-219 (1988).

Nanda I, Schartl M, Feichtinger W, Schlupp I, Parzefall J, Schmid M: Chromosomal evidence for laboratory synthesis of a triploid hybrid between the gynogenetic teleost Poecilia formosa and its host species. J Fish Biol 47:619-623 (1995).

Pauls E, Bertollo LAC: Evidence for a system of supernumerary chromosomes in Prochilodus scrofa Steindacher, 1881 (Pisces, Prochilodontidae). Caryologia 36:307-314 (1983).

Prehn LM, Rasch EM: Cytogenetic studies of Poecilia (Pisces). I. Chromosome numbers of naturally occurring poeciliid species and their hybrids from Eastern Mexico. Can J Genet Cytol 11:880-895 (1969).

Rodionova MI, Nikitin SV, Borodin PM: Synaptonemal complex analysis of interspecific hybrids of Poecilia (Teleostei, Poeciliidae). Braz J Genet 19:231-235 (1996).

Salvador LB, Moreira-Filho O: B chromosomes in $A s$ tyanax scabripinnis (Pisces, Characidae). Heredity 69:50-56 (1992).

Schartl A, Hornung U, Nanda I, Wacker R, MullerHermelink HK, Schlupp I, Parzefall J, Schmid M, Schartl M: Susceptibility to the development of pigment cell tumors in a clone of the Amazon molly, Poecilia formosa, introduced through a microchromosome. Cancer Res 57:2993-3000 (1997).

Schartl M, Nanda I, Schlupp I, Wilde B, Epplen JT, Schmid M, Parzefall J: Incorporation of subgenomic amounts of DNA as compensation for mutational load in a gynogenetic fish. Nature 373:6871 (1995).
Schlupp I, Parzefall J, Schartl M: Biogeography of the Amazon molly, Poecilia formosa. J Biogeography 29:1-6 (2002).

Sola L, Rossi AR, Iaselli V, Rasch EM, Monaco PJ: Cytogenetics of bisexual/unisexual species of Poecilia. II. Analysis of heterochromatin and nucleolar organizer regions in Poecilia mexicana mexicana by C-banding and DAPI, quinacrine, chromomycin A3, and silver staining. Cytogenet Cell Genet 60:229-235 (1992a).

Sola L, Iaselli V, Rossi AR, Rasch EM, Monaco PJ: Cytogenetics of bisexual/unisexual species of Poecilia. III. The karyotype of Poecilia formosa, a gynogenetic species of hybrid origin. Cytogenet Cell Genet 60:236-240 (1992b).

Sola L, Rossi AR, Bressanello S, Rasch EM, Monaco PJ: Cytogenetics of bisexual/unisexual species of Poecilia. V. Unisexual poeciliids with anomalous karyotypes from northeastern Mexico. Cytogenet Cell Genet 63:189-191 (1993).

Sola L, Galetti PM Jr., Monaco PJ, Rasch EM: Cytogenetics of bisexual/unisexual species of Poecilia. VI. Additional nucleolus organizer region chromosomal clones of Poecilia formosa (Amazon molly) from Texas, with a survey of chromosomal clones detected in the Amazon molly. Heredity 78:612619 (1997).

Vicente VE, Moreira-Filho O, Camacho JPM: Sex-ratio distortion associated with the presence of a B chromosome in Astyanax scabripinnis (Teleostei, Characidae). Cytogenet Cell Genet 74:70-75 (1996).

White MJD: Animal cytology and evolution, $3^{\text {rd }}$ ed. (Cambridge University Press, London 1973).

Ziegler CG, Lamatsch DK, Steinlein C, Engel W, Schartl M, Schmid M: The giant B chromosome of the cyprinid fish Alburnus alburnus harbours a retrotransposon-derived repetitive DNA sequence. Chromosome Res 11:23-35 (2003). 